\title{
FORMAÇÃO DE PROFESSORES: CONSTRUINDO CENÁRIOS INCLUSIVOS
}

\section{TEACHER'S TRAINING: BUILDING INCLUSIVE SCENARIOS}

\author{
Lucila Maria Costi Santarosa \\ UAB/UFRGS/NIEE \\ lucila.santarosa@terra.com.br \\ Débora Conforto \\ UAB/UFRGS/NIEE \\ conforto@terra.com.br
}

\begin{abstract}
Resumo: O presente artigo apresenta um curso de formação de professores de instituições públicas, na modalidade a distância, em diferentes cenários socioculturais brasileiros e ibero-americanos, no âmbito da Informática na Educação Especial. Promovidos pelo SEESP/MEC (Secretaria de Educação Especial, Ministério da Educação e Cultura) e desenvolvido sob a responsabilidade da UAB (Universidade Aberta do Brasil) e da UFRGS (Universidade Federal do Rio Grande do Sul), esse tempo e esse espaço de formação continuada docente têm assumido como escopo o respeito e a valorização da diversidade humana. Nessa perspectiva, ao mesmo tempo em que indicamos pontos de fragilidade no design de cursos em EAD, descrevemos possibilidades de projetar e concretizar o conceito de Ergonomia Cognitiva e social.
\end{abstract}

Palavras-chave: Formação de Professores; Ergonomia Cognitiva; Acessibilidade; Inclusão Sociodigital.

\begin{abstract}
This article presents and discusses a course for teachers of brazilian and latin American public institutions in distant mode in the Informatics in Special Education. Hosted by MEC / SEESP (Ministry of Education and Culture and Department of Special Education), and developed under the responsibility of the UAB (Open University of Brazil) and UFRGS (Federal University of Rio Grande do Sul), that time and space for continued education teaching have as its objective respect and appreciation of human diversity. From this perspective, we indicate points of weakness in the design of courses in distant mode, and describe, at the same time, the possibilities of constructing and developing the concept of Cognitive and Social Ergonomics.
\end{abstract}

Keywords: Teacher's training; Cognitive Ergonomics; Accessibility, Inclusion Sociodigital

\section{Introdução}

A formação docente é uma das temáticas que se faz presente nas agendas pedagógicas que assumem o desafio de qualificar o processo educativo no contexto brasileiro. Para responder ao imperativo social e ético de capacitar professores para a docência em países de dimensões continentais como o Brasil, ambientes digitais/virtuais de formação a distância têm operado, indiscutivelmente, como interfaces de aprendizagens significativas.

Na perspectiva da modalidade a distância, por meio de projetos patrocinados pelo MEC (Ministério da Educação), em especial pela SEESP ( Secretaria da Educação Especial), a equipe de pesquisadores do NIEE (Núcleo de Informática na Educação Especial) da UFRGS (Universidade Federal do Rio Grande do Sul) vem participando ativamente da criação de alternativas metodológicas para a formação de professores, na modalidade a distância, no campo técnico-metodológico da Informática na Educação Especial (SANTAROSA, 1997). 
Respondendo positivamente às políticas públicas de inclusão sociodigital, o grupo de pesquisa do NIEE/UFRGS passou a integrar o Programa de Formação Continuada em Educação, no âmbito da Universidade Aberta do Brasil (UAB). Como participante da Rede de Formação Continuada de Professores na Educação Especial, pesquisadores do NIEE/UFRGS buscam capacitar educadores para apoiar 0 desenvolvimento afetivo e sociocognitivo na área da comunicação para a diversidade humana.

Aproximando professores dos saberes e recursos técnico-metodológicos da Informática na Educação Especial, o Curso de Formação em Tecnologias de Informação e Comunicação Acessíveis justifica-se por assumir como meta a construção do perfil do profissional que mediará o processo educativo junto à diversidade humana. Ao trazermos os objetivos presentes nos documentos assinados pelo MEC/SEESP (BRASIL, 2008), e que gestam a construção da ação inclusiva nas instituições educativas, apontamos para a relevância do campo de saber das tecnologias computacionais acessíveis para impulsionar sua concretização:

- Garantir a transversalidade das ações da educação especial no ensino regular. Contemporaneamente, não há como projetar a transversalidade entre modalidades de ensino - especial e regular - sem uma efetiva apropriação das ferramentas de pesquisa, comunicação, interação, construção e publicação de conteúdo para a web. Recursos que passam a ser disponibilizados em escolas inclusivas, "laptops com sintetizadores de voz, software de comunicação alternativa e demais ajudas técnicas” (Decreto $N^{\circ} 6571$, Art. $3^{\circ}$, parágrafo $2^{\circ}$ ), conquistam sentido e significado ao possibilitar processos de mediação pedagógica, pela interface da rede mundial de computadores, e ao dar visibilidade à supressão de barreiras sensoriais e físicas anteriormente impostas aos sujeitos com necessidades educacionais especiais. Conhecer as possibilidades educativas das ferramentas da Internet permite que o professor impulsione a construção de práticas de inclusão para além do tempo e do espaço da sala multifuncional, para fazer repercutir junto ao professor no espaço da sala de aula, local em que, por excelência, a inclusão deve ocorrer.

- Fomentar o desenvolvimento de recursos didáticos e pedagógicos que eliminem barreiras no processo de ensino e aprendizagem [...], assegurar condições para a continuidade de estudos nos demais níveis de ensino. Promover a alfabetização e a fluência digital docente e impulsionar a apropriação das ferramentas de comunicação e interação síncrona e assíncrona junto a todos os discentes são ações centrais para que adjetivos como democrático e universal possam figurar ao lado das palavras Educação Inclusiva.

- A formação de gestores, educadores e demais profissionais da escola para a educação inclusiva, no que se refere ao campo de saber das tecnologias de informação e de comunicação, não pode e não deve ser reduzida somente à apropriação das funcionalidades de Tecnologia Assistiva. A inclusão sociodigital é o processo mediante o qual sujeitos obtêm acesso à tecnologia digital e se capacitam para o desenvolvimento de competências para a promoção de uma maior qualidade de vida. Há basicamente dois espaços para a promoção da inclusão sociodigital: o primeiro, mais amplo, inclui todos os tempos e espaços não-escolares, e o segundo, mais restrito, é promovido por ações de alfabetização 
tecnológica desencadeadas ao longo do processo de escolarização. Inúmeras iniciativas públicas e privadas têm respondido ao desafio da democratização e universalização da informação, mas, no contexto brasileiro, em que $95 \%$ da população em idade escolar está na escola (FERNANDES, 2009), são as instituições de ensino que fortemente respondem a esse projeto ético de apropriação de artefatos e técnicas digitais para promover e possibilitar a participação de todos, sem exclusão, nos diferentes tempos e espaços culturais. Tecnologias digitais operam com interfaces de comunicação e de mobilidade para a superação de limitações físicas e sensórias, entretanto a conquista do direito de exercício de cidadania somente assumirá a dimensão da equidade social quando a discussão sobre acessibilidade à web, objetos de aprendizagem Acessíveis e a análise de altas tecnologias digitais chegarem também nos espaços escolares.

- A formação docente como compromisso com um projeto social, político e ético que contribua para a consolidação de uma nação soberana, democrática, justa e inclusiva e que promova a emancipação dos indivíduos e grupos sociais. Tal princípio aponta para a importância de, em um curso de formação sobre as tecnologias de informação e comunicação acessíveis, trabalhar de forma integrada ao processo de aprendizagem de sujeitos com necessidades educacionais especiais, possibilitando romper com a prática reducionista de usuários e consumidores de produtos culturais, para assumir a postura de produtores de informação em diferentes mídias culturais. A garantia da continuidade de estudos passa pela apropriação das funcionalidades técnicometodológicas das ferramentas de Educação a Distância (EAD).

- A garantia de padrão de qualidade dos cursos de formação de docentes ofertados pelas distintas instituições formadoras na modalidade presencial e a distância somente será atingida quando os diferentes campos de saber da Informática na Educação Especial forem percorridos e apropriados pelos profissionais em processo de capacitação. Ações de inclusão sociodigital tendem ao êxito quando a utilização das tecnologias de informação e de comunicação focaliza a transformação e não a tecnologia. Aproximar educadores do Estado da Arte no campo da Informática na Educação Especial é projetar uma ergonomia cognitiva no cenário escolar, é forjar um tempo-espaço sociocultural ajustado às especificidades humanas, é abrir novas possibilidades para edificar projetos de vida para sujeitos marcados pela face negativa da deficiência. A garantia da qualidade do curso de Formação Continuada de Professores em Tecnologias de Informação e Comunicação Acessíveis efetiva-se quando recursos tecnológicos são assumidos como objetos catalisadores da inteligência coletiva.

- Pesquisas internacionais e nacionais demonstram que a Informática na Educação Especial tem produzido mais resultados positivos no que se refere ao desenvolvimento cognitivo e sócio-afetivo de alunos em diferentes contextos educacionais. Isso reforça o trabalho do grupo NIEE/UFRGS e motiva a continuidade na formação de educadores nessa área, na certeza de que, por essa via, as tecnologias digitais de informação e de comunicação chegarão aos espaços do sistema educacional brasileiro, contribuindo para a inclusão sociodigital e a criação de espaços digitais para atender a demanda nacional de formação de professores. 


\section{Curso de formação continuada de professores em tecnologias de informação e comunicação acessíveis}

O curso de formação continuada de professores de escolas públicas na perspectiva da Educação Inclusiva, com abrangência nacional, busca auxiliar docentes no uso das Tecnologias da Informação e da Comunicação Acessíveis e na construção de ações pedagógicas para o atendimento educacional especializado (AEE), com o objetivo de apoiar processos de aprendizagem de alunos com necessidades educacionais especiais, nas respectivas unidades de ensino. O curso é desenvolvido na modalidade a distância, utilizando, para isso, as ferramentas de mediação e de comunicação disponibilizadas pelo ambiente digital de aprendizagem - TELEDUC. A metodologia de ensino, por ser na modalidade EAD, prevê o desenvolvimento de estratégias de aprendizagem e a publicação na plataforma do curso das atividades previstas para cada componente da base curricular, por meio de uma sequência de fases: (1) Fase de Sensibilização: apresentação e sensibilização às temáticas em foco, por meio de conferências pela Internet, via ferramentas de comunicação síncrona (chat) e assíncrona (correio eletrônico, fóruns...); (2) Fase de Imersão: vinculação ao contexto da escola, diagnosticando a realidade escolar e trazendo casos existentes para a proposição das possíveis formas de intervenção; (3) Fase de Problematização: apropriação conceitual por meio de interações síncronas e assíncronas; (4) Fase de Consolidação: construção e reconstrução conceitual, apresentando os resultados edificados ao longo do processo de aprendizagem individual e coletivo.

A opção metodológica do curso centra-se na interação de seus participantes. Nessa dinâmica, o professor, ao apropriar-se das tecnologias digitais, desenvolve atividades junto aos seus alunos especiais, compartilha com seus pares, formadores e tutores e constrói, coletivamente, soluções e alternativas para a inclusão escolar e sociodigital. A organização curricular (Figura 1) envolve seis módulos, configurando um campo de saber técnico-metodológico para exercício da docência junto à diversidade humana.

Formação Continuada de Professores em Tecnologias de Informação e Comunicação Acessiveis

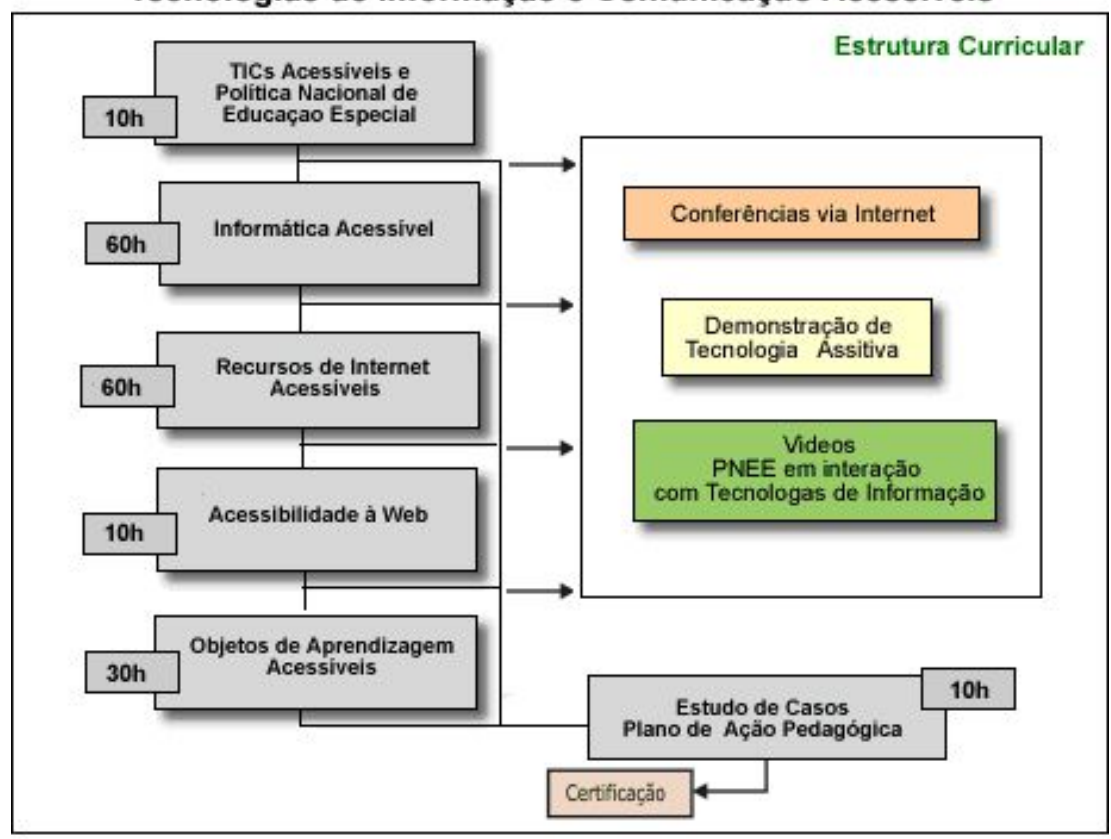

Figura 1 - Estrutura curricular do curso 
O curso tem duração de 180 horas apoiado pelos recursos e ferramentas do ambiente do curso - espaços de interação e comunicação, materiais de apoio teórico e técnico-metodológico, recursos de software, videoconferência, vídeos-, com o objetivo de projetar uma intervenção direta do professor em seu contexto de trabalho junto aos alunos com necessidades educativas especiais.

\section{Respeito e valorização da diversidade humana na modalidade EAD: a produção de uma ergonomia cognitiva}

Ergonomia, do grego ergon (trabalho) e nomos (normas, regras, leis), aborda amplos e diferentes aspectos que podem intervir nas atividades sociais, culturais e econômicas, com o objetivo de otimizar o bem - estar humano e o desempenho global do sistema. A ergonomia é cognitiva (ABRAHAO, SILVINO, SARMET, 2005) quando seu foco de problematização recai sobre os processos mentais que afetam as interações entre os seres humanos e o sistema sociocultural, entre elas, a interação de indivíduos com recursos tecnológicos.

Colocar em prática os princípios que ratificam a educabilidade da diversidade humana, meta assumida pela equipe técnico-pedagógica UAB/UFRGS/NIEE, enfrentou, no próprio ambiente do curso, seu primeiro desafio: projetar sua interface sob o foco de uma ergonomia cognitiva. Em curso de formação a distância, desenvolvido a partir de 2004, ao contar com a participação de professores cegos e surdos, pontos de obscuridade e de fragilidade na funcionalidade das ferramentas do ambiente TELEDUC foram revelados e apontados como aspectos que dificultaram ou, até mesmo, impossibilitaram a efetiva participação de professores com necessidades especiais.

Era a fragilidade na interação da diversidade humana que conquistava visibilidade e colocava em xeque temáticas abordadas ao longo do curso: a inclusão escolar, o uso de Tecnologia Assistiva e os princípios de Acessibilidade à Web (CONFORTO, SANTAROSA, 2002).

A dificuldade experienciada por professores surdos pela frágil apropriação da linguagem alfabética e a ausência da tradução das informações para LIBRAS, ou por professores cegos, pela impossibilidade de usufruir as vantagens de uma comunicação síncrona, ou pelas restrições impostas por interfaces computacionais extremamente gráficas para os usuários que utilizam tecnologias de leitores de tela, tornou-se um desafio o qual fez com que o projeto técnico-pedagógico do curso de formação no âmbito da Informática na Educação Especial assumisse uma nova configuração. A investigação trilhou na busca de ações interdisciplinares condizentes com a ergonomia cognitiva para orientar a atuação da equipe técnico-pedagógica responsável pelo curso com o objetivo de ajustar a interface do ambiente digital do curso aos princípios de equidade sociodigital expressos nas diretrizes de Acessibilidade à Web e de Desenho Universal, um movimento projetado para garantir o convite e a permanência da diversidade no curso por meio do reconhecimento do outro e da diferença.

A promoção da inclusão sociodigital passa, indiscutivelmente, pela busca da acessibilidade, um conceito que deve trazer em seu escopo a flexibilização de acesso a usuários que revelam algum tipo de fragilidade, especificidades que possam produzir restrições aos mecanismos de navegação e à operação com software e com hardware. No sentido mais amplo, o termo acessibilidade deve ser entendido como aproximação, uma ação que possibilite a remoção de barreiras que impedem a diversidade humana de participar efetivamente de atividades socioculturais no contexto da sociedade, incluindo serviços, produtos e informação. 


\subsection{A ergonomia cognitiva: na dimensão técnica}

Ambientes tecnológicos para apoiar processos educativos na modalidade a distância, amplamente utilizados no contexto brasileiro - MOODLE e TELEDUC -, vem sendo problematizados por inúmeras pesquisas e começam a dar visibilidade às fragilidades dessas interfaces em acolher e potencializar uma interação mais qualificada para a diversidade humana. Como apontam as pesquisas de Sonza (2008), as caixas de contexto para a seleção de opções (editar, ver, abrir, renomear, mover, mudar de posição), a barra de ícones para formatação de textos nos editores online e os recursos de filtragem de informações proporcionados pelas caixas combinadas ilustram recursos computacionais de ambientes digitais não-sintonizados com os princípios de Desenho Universal, aspectos que dificultaram a acessibilidade, a navegabilidade e a comunicabilidade para usuários com limitação visual que utilizam leitores de tela.

Para aproximar essa interface dos princípios que normatizam o Desenho Universal, (1) as imagens foram etiquetadas, ou seja, todo o conteúdo organizado por meio imagético foi descrito para garantir sua apropriação por parte dos educadores com limitação visual; (2) os materiais foram construídos respeitando o contraste entre cor do fundo e texto, sem a utilização de frames ou de tabelas para a organização do conteúdo; (3) foram inseridas interfaces mais textuais, com linguagem direta e objetiva, buscando aproximar sujeitos videntes e não-videntes, com o objetivo de aumentar e impulsionar a cooperação, a autonomia e a co-responsabilidade pelo processo educativo; (4) todas as leituras discutidas nas disciplinas do curso foram apresentadas nas versões .doc e .txt para permitir a apropriação de seu conteúdo para usuários que utilizam leitores de tela.

A comunicação síncrona por meio do bate-papo foi, sem dúvida, a ferramenta que revelou o maior número de questionamentos por parte de professores-cursistas cegos que utilizam leitores de tela. Subgrupos de pesquisa do NIEE/UFRGS investigam e implementam ferramentas para dar suporte à comunicação síncrona, uma vez que essas tecnologias são descritas e implementadas para um todo normal e homogêneo, sem considerar a diversidade humana e as normas de acessibilidade que foram criadas frente às dificuldades inerentes às diferenças humanas. Para garantir a comunicação em tempo real para todos os participantes do curso, desde 2008, encontra-se em fase final de validação, uma ferramenta de bate-papo falado, EVOC (BARWALDT, 2008), que visa proporcionar acessibilidade a cegos, ampliando a interação de todos os participantes do ambiente, além do uso de outras ferramentas de comunicação, como os recursos de voz do MSN e do SKYPE.

A linguagem alfabética, para sujeitos com limitação auditiva, configura-se como uma forma de comunicação e de pensamento inerte e artificial, revelando-se, muitas vezes, como um aspecto restritivo para a apropriação das diferentes temáticas abordadas ao longo do curso. Essa dificuldade já vinha sendo respondida em edições anteriores do curso pela equipe técnico-pedagógica da UAB/UFRGS/NIEE, de forma incipiente, ao designar um monitor específico para as turmas que apresentavam professores surdos. A partir de nossa investigação, foi possível potencializar essa estratégia por meio da adaptação dos materiais do curso à especificidade dos professores-cursistas com limitação auditiva. Dessa forma, a insatisfação pela perda de autonomia em seu processo de aprendizagem técnico-pedagógica ao longo do curso começava a ser respondida com a elaboração de um glossário com termos e conceitos apresentados ao longo de cada disciplina do curso.

Para garantir ao professor-cursista com limitação auditiva uma maior autonomia em seu processo de aprendizagem, a linguagem utilizada na construção das agendas, atividades e leituras foi também revista. Responder aos desafios de uma linguagem que 
se mostrava como um fator excludente exigiu que aspectos linguísticos fossem contemplados na organização da informação textual: (1) alternância entre letras maiúsculas e minúsculas, para tornar a leitura mais fácil e mais rápida, ampliando as possibilidades de compreensão do texto; (2) uso de marcadores e de listas para aumentar a velocidade de leitura do texto; (3) estruturação das informações em pequenos blocos, estratégia de diagramação que retarda a fadiga e aumenta a apropriação do conteúdo disponibilizado na tela do computador; (4) textos com linhas curtas, diminuindo o esforço de movimentação dos olhos, minimizando o cansaço na leitura; (5) uso de linguagem direta e simples.

Essas estratégias de customização para a organização da informação começaram a atender as necessidades de usuários que têm na linguagem de sinais sua primeira língua. As palestras e vídeos disponibilizados pelo curso foram traduzidos em LIBRAS para aumentar a legibilidade do conteúdo problematizado nas diversas temáticas da Informática na Educação Especial desenvolvidas ao longo do curso. Por meio dessas estratégias, buscamos enfrentar o desafio ampliando os espaços digitais e os recursos que o grupo de pesquisa do NIEE já desenvolvia. A figura 2 sintetiza os recursos utilizados e adaptados para compor a interface do curso, ampliando a possibilidade de edificar redes de aprendizagem.

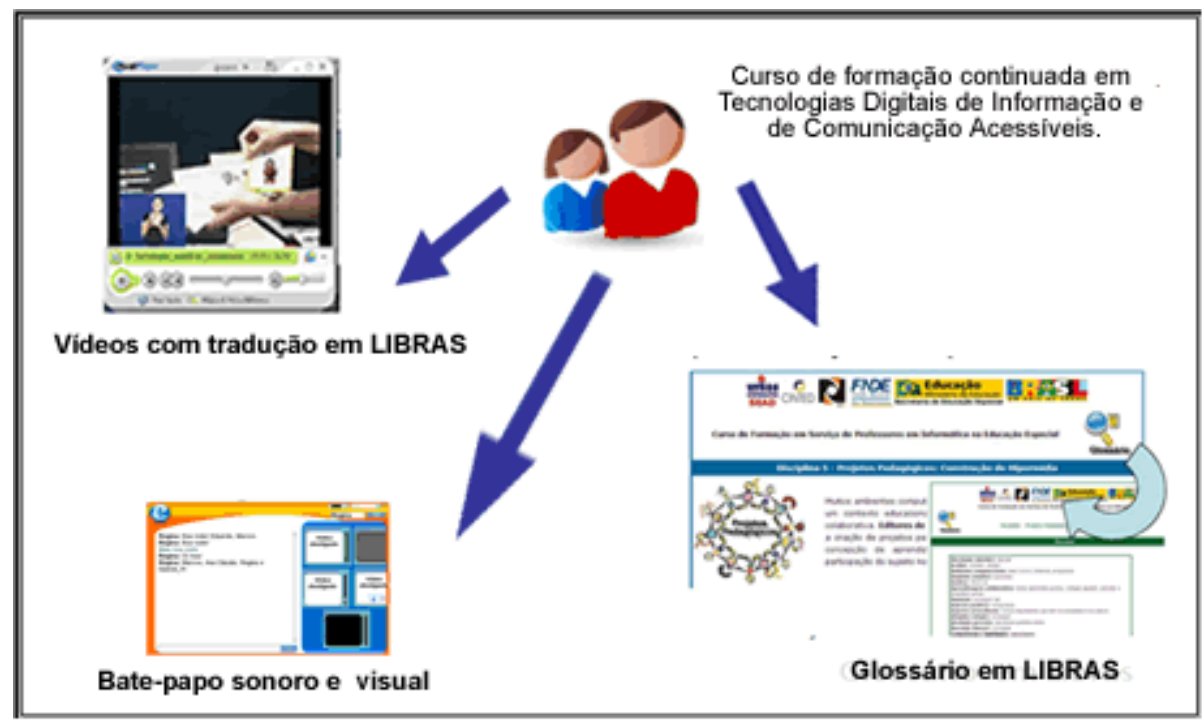

Figura 2 - Ferramentas e recursos para ampliação da acessibilidade ao ambiente do curso

\section{2 . A ergonomia cognitiva: na dimensão social}

Projetada a interface técnica sob a lógica de uma ergonomia cognitiva, é preciso analisar seus efeitos e os movimentos desencadeados a partir da customização de interfaces para projetar um novo design técnico-pedagógico para cursos de formação continuada docente. Ao dar visibilidade ao jogo experienciado entre limites e possibilidades de intervenção para a superação de práticas educativas que colocam na exterioridade das atividades socioculturais a diversidade humana, respondemos ao terceiro aspecto que compõe a construção de uma ação de inclusão sociodigital: apropriação de tecnologia para edificar projetos de vida. Muitos são os aspectos que podem ratificar a concretização desse importante aspecto para promoção da inclusão sociodigital; escolhemos um deles, por refletir a ação de dois atores na apropriação dos saberes e da materialidade da Informática na Educação Especial: o educador e o aluno. $\mathrm{O}$ recorte que apresentamos a seguir ilustra os saberes problematizados ao longo das 
seis disciplinas do curso, cristalizados na conquista de uma menina que, por problemas físicos, ficou à margem de muitas experiências educativas. Um novo olhar para a diversidade humana aconteceu no município do interior brasileiro, uma ação ética e estética de respeito e valorização da diversidade humana, ilustrada nas palavras da professora em processo de formação no âmbito da Informática na Educação Especial:

Não tenho palavras para expressar o quanto o curso está sendo gratificante para mim. D. é uma linda menina que teve parte dos membros superiores e inferiores amputados aos 3 anos. Hoje, aos 10 anos de idade, nos surpreendeu com sua alegria e vontade de vencer tudo que lhe é proposto a fazer. No computador, mesmo sem ter contato antes, parece que já é intima dessa máquina! Dominou o mouse como qualquer outra criança, ou até melhor. Como ainda não temos acessórios corretos, ela utilizou para digitar um lápis com uma borracha na ponta para não escorregar nas teclas, mas em breve vou providenciar um adaptador para que ela possa utilizar os dois braços. Fiquei admirada com o teclado de conceitos, o ponteiro de cabeça que pode ser afixado diversos tipos de acessórios, possibilitando teclar, pintar, pegar objetos, a tela sensível ao toque, o reconhecimento de voz. Foi fundamental para que eu tivesse uma visão mais ampla do funcionamento das ajudas técnicas e de suas possibilidades educativas. Eu não imaginava que isso era possível. [D.G.A.S. - Professora-cursista - 2007].

\section{Ampliando espaços de interação: para além das fronteiras brasileiras}

Desde sua primeira edição, o Curso de Formação Continuada em Tecnologias de Comunicação e Informação Acessíveis, qualificou professores da rede pública, atendendo a todos os estados brasileiros. Na edição de 2009/2010, o curso tem seu espaço de atuação ampliado, passando a atender professores de outros países do continente americano.

Das 45 turmas que compõem a atual edição do curso, temos uma turma formada por professores da Argentina, do Uruguai, do Panamá e da Costa Rica, o que tem possibilitado a emergência de novos e importantes dados para a construção e reflexão de ações projetadas nas políticas públicas no âmbito da Educação, mais especificamente, da Educação a Distância e da Informática na Educação Especial. Essa ampliação abre um espaço de diálogo entre países, além de dinamizar as trocas de experiências entre povos com dimensões e contexto histórico-culturais similares e, também, extremamente diferenciados. A diferença de idioma não foi impedimento para o intercâmbio de ideias e o processo de apropriação da experiência brasileira, uma vez que os materiais de apoio não foram traduzidos. A plataforma TELEDUC foi utilizada na versão de língua espanhola, bem como foram traduzidos alguns materiais básicos que compunham o plano do curso, as agendas e as atividades. Os bate-papos foram realizados na língua espanhola, contando para isso com um formador e um tutor com domínio no idioma. Os depoimentos feitos pelos professores cursistas revelam dados importantes sobre a experiência realizada. As falas abaixo exemplificam, quando indagados sobre as limitações do curso, os aspectos positivos e os desdobramentos que viabilizam um curso desse tipo:

\footnotetext{
"En nuestra institución recibieron muy bien toda la información, hicimos reuniones para compartir el material y esperamos trabajar en un futuro inmediato con el mismo, según se presenten alumnos con NEE y tengamos los equipos adecuados."

"Los puntos positivos del curso fue intervenir en una plataforma virtual con un nivel académico muy bueno, el acceso al manejo de recursos tecnológicos y de información muy actualizados, la variedad de propuestas que exigían reflexionar sobre la actualidad de cada realidad en cada país, conocer el nivel de enseñanza en otras instituciones y la posibilidad de manejar software de actualidad."

"Viable e importante dar continuidad al proceso de inclusión digital, hoy en día necesitamos estar actualizados, formar redes de apoyo y de formación, estaria en la mejor disposición de continuar recibiendo cursos como el llevado con ustedes que me permitan refrescar conocimientos, adquirir nuevas estrategias de aprendizaje y mediación con los estudiantes con NEE."
} 


\section{Resultados: a produção de conhecimento e a concretização de uma Educação Inclusiva}

As palavras das professoras que encerraram a seção anterior deste artigo ratificam a importância de processos de formação continuada, na modalidade a distância, projetada pela SEESP/MEC, pela possibilidade de espraiar o saber e a materialidade da Informática na Educação Especial nos diferentes pontos do Brasil e, na última versão, para países de língua espanhola. A partir de instrumentos de avaliação do curso, professores afirmam e valorizam o potencial das tecnologias digitais acessíveis como pontes e rampas para a inclusão digital e social de PNE (SANTAROSA, et al, 2007): [...]na contribuição do curso no processo de inclusão e no avanço dos alunos no processo ensino e aprendizagem; na grande vantagem que o curso oferece para que os professores possam utilizar os recursos disponíveis com os seus alunos; no que um curso na modalidade a distância representa na possibilidade e no caminho para uma socialização sem fronteiras; na possibilidade dos professores terem condições de estarem situados em seus locais de trabalho e aprendendo sobre as novidades do mundo tecnológico em uma sociedade tão excludente onde os alunos necessitam das tecnologias para estarem inseridos no contexto social.

A produção de conhecimento conquista visibilidade, na produção de um livro Tecnologias Digitais Acessíveis (SANTAROSA, et al., 2010), com o registro das estratégias técnico-pedagógicas tecidas nas comunidades de aprendizagem forjadas nas diferentes edições do curso e, que passa a compor o material didático do curso, entregue a cada participante de forma gratuita. Acompanha essa obra, um DVD com um conjunto de recursos tecnológicos (softwares educativos e tecnologias acessíveis), materiais de apoio, para garantir a continuidade da formação e viabilizar a concretização de projetos pedagógicos nas diferentes unidades educativos brasileiras. Estão inseridas nesse DVD as palestras que trazem o pensar de diferentes especialistas relacionados à temática da Educação Inclusiva. Essa publicação no campo de saber da Informática na Educação contou com o apoio financeiro da SEESP/MEC.

\section{Reflexões parciais}

Buscamos, com este artigo, colocar em discussão a temática da inclusão sociodigital pela interface de um curso de formação a distância em Informática na Educação Especial. Diminuindo a sobrecarga cognitiva e vivenciando um exercício de autonomia, o Curso de Formação Continuada em Tecnologias de Comunicação e de Informação Acessíveis vem, ao longo de suas diferentes edições, permitindo aos professores-cursistas a conquista do poder da palavra, registrada nas diversas ferramentas do ambiente virtual do curso, para dar visibilidade à riqueza de atuações de educadores. Professores-cursistas, em sua maioria isolados no cenário multicultural brasileiro, vivendo a carência de recursos materiais e humanos, são estimulados e impulsionados pelo saber, pela informação, pela formação e, principalmente, pela construção e vivência de um espaço digital/virtual educativo estruturado para a nãodiscriminação, um real exercício da lógica da inclusão.

Projetar uma ergonomia cognitiva, agora em cenários nacional e internacional, tem possibilitado que um importante tempo-espaço sociocultural seja ajustado às especificidades de seus usuários e aberto a novas possibilidades para edificar projetos de vida para sujeitos marcados pela face negativa da deficiência. Mais do que garantir e valorizar a participação de usuários surdos e cegos, pensar a diversidade e projetar a 
inclusão, permitiu à equipe técnico-pedagógica UAB/UFRGS/NIEE, ratificar e sublinhar a faceta educativa para o campo de saber da Informática na Educação Especial. São os recursos tecnológicos operando como objetos catalisadores da inteligência coletiva e tornando-se entidades que propiciam o acolhimento da diversidade.

\section{Referências}

ABRAHAO, Júlia Issy; SILVINO, Alexandre Magno Dias and SARMET, Maurício Miranda. Ergonomia, cognição e trabalho informatizado. Psic.: Teor. e Pesq. [online]. 2005, vol.21, n.2, pp. 163-171. ISSN 0102-3772. doi: 10.1590/S0102-37722005000200006.

BARWALDT, R. Ferramenta com recurso de voz: uma proposta para favorecer o processo de interação e inclusão dos cegos em ambientes virtuais de aprendizagem. Tese (Doutorado em Informática na Educação) - Universidade Federal do Rio Grande do Sul, 2008.

BRASIL. Decreto ${ }^{\circ} 6.571$, de 17 de setembro de 2008. Dispõe sobre o atendimento educacional especializado, regulamenta o parágrafo único do art. 60 da Lei nํㅜ 9.394, de 20 de dezembro de 1996, e acrescenta dispositivo ao Decreto nํㅜ 6.253, de 13 de novembro de 2007.

CONFORTO, D. e SANTAROSA, L. M. C. Acessibilidade à Web: Internet para Todos. Revista de Informática na Educação: Teoria, Prática - PGIE V.5 Nº 2 p.87-102. nov./2002.

FERNANDES, C.O. Fracasso escolar e escola em ciclos: tecendo relações históricas, políticas e sociais. Disponível em:

http://www.campinas.sp.gov.br/arquivos/fracassoescolareescolaemciclos.pdf. Acesso em: 26 nov. 2009.

SANTAROSA, L. (org.); CONFORTO et al.; Tecnologias digitas acessíveis. Porto Alegre: JSM Comunicação Ltda., 2010.

SANTAROSA, L. M. C. e CONFORTO, D. Eduquito: uma discussão técnico-pedagógica da inclusão em diferentes cenários sociais. In: VIII Congreso Internacional de Informática y Educación Especial-CIIEE 2009. San Jose, Costa Rica, 2009.

SANTAROSA, L. M. C.; PASSERINO, L. M. ; CARNEIRO, M. L. ; GELLER, M. CONFORTO, D. Formação de Professores: referencias na construção da acessibilidade para ambientes virtuais de educação a distancia. Educação (Porto Alegre), v. 3, p. 531-545, 2007.

SANTAROSA, L.M.C. Projeto Nacional de Informática na Educação Especial. SEESPMEC. 1997 (Projeto inicial apresentado, como consultora, a SEESP- MEC).

SONZA, A. P. Ambientes virtuais acessíveis sob a perspectiva de usuários com limitação visual. Tese (Doutorado em Informática na Educação) - Programa de Informática na Educação. Universidade Federal do Rio Grande do Sul. 2008. 